\title{
Penoscrotal defect: a functional, esthetic, and psychological challenge
}

\author{
Durga Karki, Pankaj Kumar Patel, Ravi Prakash Narayan
}

Department of Burns, Plastic and Maxillofacial Surgery, Safdarjung Hospital, New Delhi 110029, India.

Address for correspondence: Dr. Durga Karki, Department of Burns, Plastic and Maxillofacial Surgery, Safdarjung Hospital, New Delhi 110029, India. E-mail: dkarki10@yahoo.co.in

\begin{abstract}
Aim: Penoscrotal defects may be caused by a variety of events. Reconstruction of the penoscrotal region is required not only for aesthetic appearance but also for functional and psychological reasons. Numerous techniques have been described for penoscrotal reconstruction reflecting the challenge and complexity of the region involved. This suggests that no single method is satisfactory for all types and degrees of tissue defects. This prospective study was conducted in a tertiary care hospital in India, over a period of 5 years. Methods: Eighteen patients with penoscrotal defects of varying etiology were included in the study and underwent different surgical techniques. Age of the patients ranged from 20 to 60 years. The etiology of penoscrotal defect was Fournier's gangrene in 12 cases, trauma in 4 cases, and burn in 2 cases. The patients with Fournier's gangrene were initially treated by debridement, drainage, and antibiotics. The penoscrotal defects were treated with local flap advancement with skin grafting $(n=7)$, pedicled anterolateral thigh flap $(n=4)$, gracilis muscle flap with split skin grafting $(n=4)$, and medial thigh flap $(n=3)$. Results: There was complete healing in 16 patients with minor complications in the form of partial skin graft loss $(n=1)$ and wound dehiscence $(n=1)$. Results were highly satisfactory in 6 patients, satisfactory in 8 patients, and not satisfactory in 4 patients. Scarring at the donor site was limited and acceptable. Conclusion: The vast arsenal of options for penoscrotal defect coverage ranges from skin grafting to flaps, and every case needs a customized approach with regard to its feasibility, outcome, and complication rate. Flaps should be the preferred choice over the skin grafts because of the superior functional and aesthetic results and better compliance.
\end{abstract}

Key words:

Anterolateral thigh flap; gracilis muscle flap; penoscrotal defect

\section{INTRODUCTION}

Penoscrotal defects can be caused by road traffic accidents, assaults, burns, animal bites, infection/ gangrene of the region (Fournier's gangrene), postfilarial surgeries, penoscrotal construction for congenital agenesis, and gender reassignment surgeries. ${ }^{[1]}$ Reconstruction of the penoscrotal region after a

\begin{tabular}{|l|l|}
\hline \multicolumn{2}{|c|}{ Access this article online } \\
\hline Quick Response Code: & Website: \\
\hline & www.parjournal.net \\
\cline { 2 - 3 } & DOI: \\
\hline
\end{tabular}

complete loss of the overlying skin is a challenging problem. ${ }^{[2]}$ The difficulty in the reconstruction of the scrotum lies in the fact that the blood supply to the scrotal skin is destroyed when the skin and dartos muscle are avulsed or infected. ${ }^{[3]}$ Bacterial flora of the perineum, difficulty of immobilization, and contour of penis and testes makes the task of

This is an open access article distributed under the terms of the Creative Commons Attribution-NonCommercial-ShareAlike 3.0 License, which allows others to remix, tweak and build upon the work non-commercially, as long as the author is credited and the new creations are licensed under the identical terms.

For reprints contact: service@oaepublish.com

How to cite this article: Karki D, Patel PK, Narayan RP. Penoscrotal defect: a functional, esthetic, and psychological challenge. Plast Aesthet Res 2016;3:64-7.

Received: 12-03-2015; Accepted: 05-11-2015 
peno-scrotal coverage difficult. ${ }^{[4]}$ Reconstruction of the scrotum is required not only for cosmetic but also for functional and psychological reasons as well. Various surgical options have been described for penoscrotal reconstruction including split skin grafting (SSG), burying testis underneath the medial thigh skin, tissue expansion of adjacent tissues, use of local fasciocutaneous or musculocutaneous flaps, and free flaps. The aim of this study was to evaluate various reconstructive procedures for penoscrotal defects.

\section{METHODS}

A prospective study was conducted in a tertiary care hospital over a period of 5 years from March 2009 to February 2014. The operated patients were reviewed on a regular basis in context to the outcome of the procedures, complications, and further need for any intervention. Patients with penoscrotal defects of varying etiology and who had been operated using different reconstructive techniques were included in the study. Patients with uncontrolled diabetes were excluded from the study. Demographics, etiology, reconstructive technique, complications, and patient satisfaction were identified.

Patients with Fournier's gangrene were initially treated by debridement, drainage, and antibiotics. The penoscrotal defects were treated with local flap advancement with skin grafting, pedicled anterolateral thigh (ALT) flap, gracilis muscle flap with skin grafting, and medial thigh flap. Local flaps from remaining scrotal skin and adjacent medial thigh were advanced to cover the exposed testes. Any remaining defect was skin grafted. Lateral thigh flaps were raised based on the lateral circumflex femoral artery branch of the femoral artery to cover the defect [Figure 1a and b]. The donor area was primarily closed [Figure 1c and d]. Medial thigh flaps based on the medial circumflex femoral artery branch of the femoral artery was raised in the relatively bloodless subfascial plane. Gracilis muscle was separated from the distal

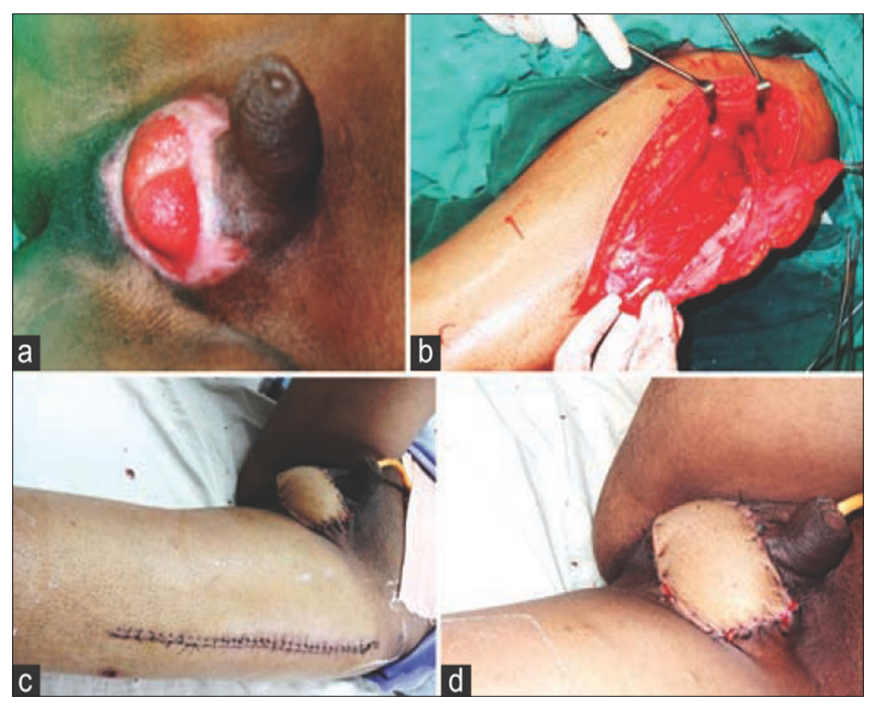

Figure 1: (a) A 28-year-old male with a history of road traffic accident presented with a penoscrotal soft tissue defect and exposed testes; (b) raised anterolateral thigh flap; (c) the bridging segment was de-epithelized, and the flap was tunneled; the defect was covered, and the donor area was primarily closed; (d) 10 days postoperative result end after dissection with preservation of the vascular pedicle present at the proximal part [Figure 2a-c]. The dissected muscle was transferred over the defect and passed through a subcutaneous tunnel [Figure 2d]. The transferred muscle was skin grafted, and the harvested site was closed primarily [Figure 2e and f]. The operated patients were followed in our hospital at a regular interval and were asked about the improvement on a global scale of $1-10$, ranging from not satisfied to highly satisfied. The penoscrotal defect etiology was Fournier's gangrene in 12 cases, trauma in four cases, and burn in two cases.

\section{RESULTS}

A total of 18 patients were identified, with a mean age of 45 years ranging from 20 to 60 years. The etiology included: $12(66.6 \%)$ cases of Fournier's gangrene, $4(22.2 \%)$ cases of traumatic injury, and $2(11.2 \%)$ cases of burn injury. The defects were treated with local flap advancement with SSG $(n=7)(40 \%)$, pedicled ALT $(n=4)$ $(22 \%)$, gracilis muscle flap with SSG $(n=4)(22 \%)$, and medial thigh flap $(n=3)(16.5 \%)$. The patients were followed on a regular basis with the mean of 8.7 months [Table 1].

Local flap advancement in combination with SSG was performed in 7 cases (5 cases following Fournier's gangrene, 1 case following trauma, and 1 case following burn injury). ALT flap was performed in 4 cases ( 3 cases following Fournier's gangrene and 1 case following trauma). Gracilis muscle flap in combination with SSG was performed in 4 patients ( 2 cases following Fournier's gangrene, 1 case following trauma, and 1 case following burn patient). See Table 1 for a summary of the patient included in the study. Medial thigh flap was performed in 3 patients ( 2 cases following Fournier's gangrene and 1 case following trauma).

A total of 6 patients developed complications. Three patients developed a postoperative wound infection and three developed wound dehiscence. Wound infection was present in 3 of the Fournier's gangrene cases, 2 of which underwent local flap advancement in combination with SSG, and 1 case underwent with ALT flap. Wound dehiscence was present in 1 case of Fournier's gangrene operated with local flap advancement and SSG, in 1 case of trauma operated with local flap advancement with SSG, and in 1 case of burn operated with gracilis muscle flap with SSG. Pedicled thigh and medial thigh flaps were associated with no complications.

Results were highly satisfactory in 6 patients, satisfactory in 8 patients, and not satisfactory in 4 patients. In patients with local flap advancement with SSG, 4 patients were satisfied, and 3 patients were not satisfied. In patients with ALT flap, 3 cases were satisfied, and 1 case was not satisfied. In patients operated with gracilis muscle flap, 3 cases were highly satisfied, and 1 case was satisfied. In patients with medial thigh flap, 2 cases were highly satisfied, and 1 case was satisfied. Scarring at the donor site was limited and acceptable. Patient compliance with 


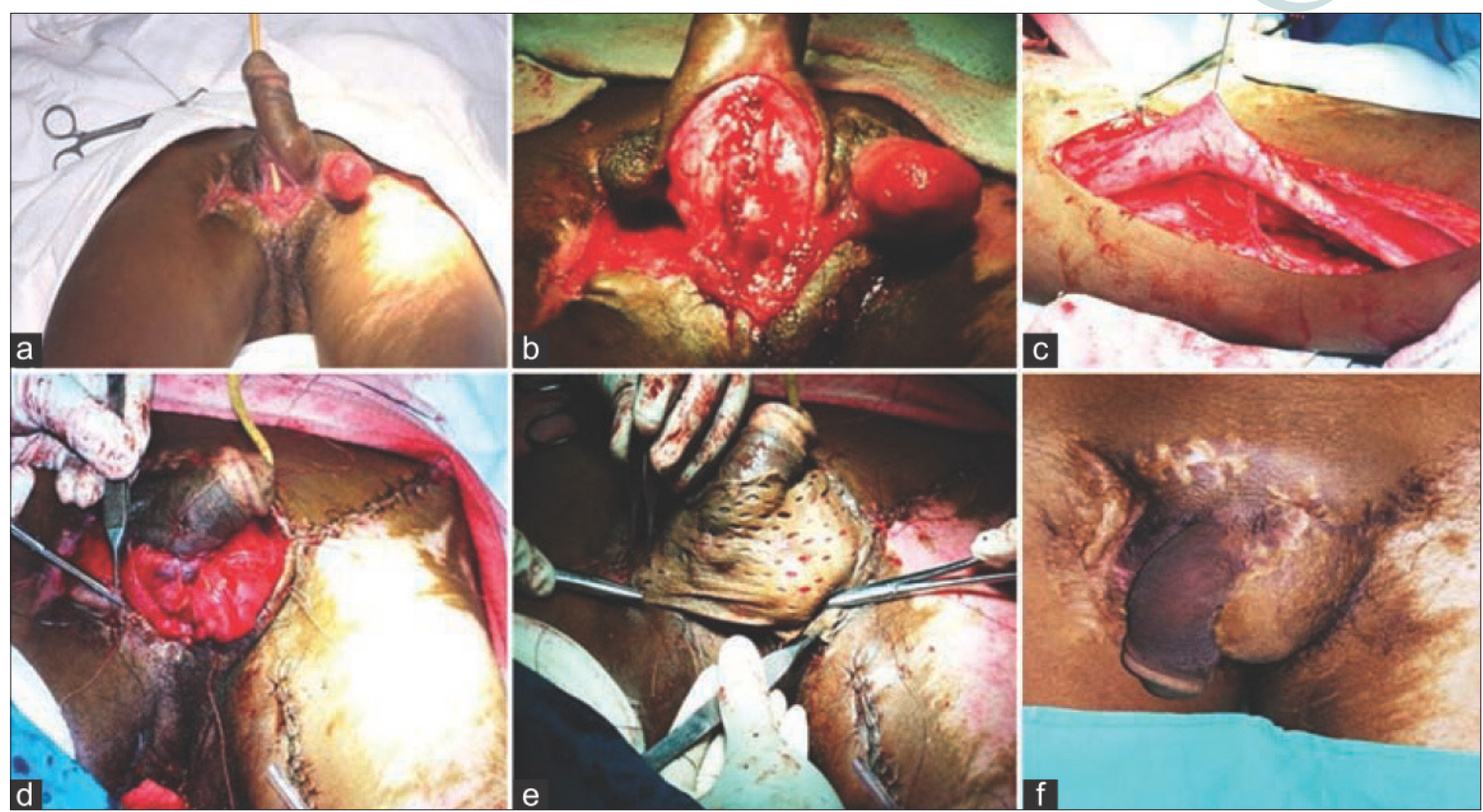

Figure 2: (a) A 30-year-old male with a history of road traffic accident presented with penoscrotal defect, exposed testes, and urethral injury; (b) debridement and urethroplasty were performed; (c) pedicled gracilis muscle flap was harvested; (d) the gracilis muscle flap was insetted; (e) split skin grafting over the muscle flap; (f) 1-year postoperative result

Table 1: Details of the patients included in the study

\begin{tabular}{|c|c|c|c|c|c|c|}
\hline $\begin{array}{l}\text { Age } \\
\text { (years) }\end{array}$ & Etiology & $\begin{array}{l}\text { Affected } \\
\text { side }\end{array}$ & $\begin{array}{l}\text { Time of } \\
\text { reconstruction }\end{array}$ & Procedure done & $\begin{array}{l}\text { Follow-up } \\
\text { (postoperative) }\end{array}$ & Complications \\
\hline 45 & Fournier's gangrene & $\mathrm{B} / \mathrm{L}$ & 27 days & Local flap advancement with SSG & 8 months (satisfactory) & - \\
\hline 56 & Fournier's gangrene & $B / L$ & 20 days & Local flap advancement with SSG & 12 month (satisfactory) & $\begin{array}{l}\text { Wound } \\
\text { infection }\end{array}$ \\
\hline 58 & Fournier's gangrene & $B / L$ & 31 days & Local flap advancement with SSG & $\begin{array}{l}6 \text { months (highly } \\
\text { satisfactory) }\end{array}$ & - \\
\hline 51 & Fournier's gangrene & $\mathrm{B} / \mathrm{L}$ & 18 days & ALT flap & 8 month (satisfactory) & - \\
\hline 48 & Fournier's gangrene & $\mathrm{B} / \mathrm{L}$ & 2 months & Local flap advancement with SSG & 10 months (unsatisfied) & $\begin{array}{l}\text { Wound } \\
\text { infection }\end{array}$ \\
\hline 42 & Fournier's gangrene & $B / L$ & 28 days & Gracilis muscle flap with SSG & $\begin{array}{l}9 \text { months (highly } \\
\text { satisfactory) }\end{array}$ & - \\
\hline 47 & Fournier's gangrene & $B / L$ & 1.5 months & Local flap advancement with SSG & 15 months (unsatisfied) & Dehiscence \\
\hline 52 & Fournier's gangrene & $B / L$ & 38 days & ALT flap & 6 months (satisfactory) & - \\
\hline 55 & Fournier's gangrene & $B / L$ & 26 days & Medial thigh flap & $\begin{array}{l}12 \text { months (highly } \\
\text { satisfactory) }\end{array}$ & - \\
\hline 47 & Fournier's gangrene & $B / L$ & 2 months & ALT flap & 5 months (unsatisfi ed) & $\begin{array}{l}\text { Wound } \\
\text { infection }\end{array}$ \\
\hline 57 & Fournier's gangrene & $B / L$ & 2 months & Medial thigh flap & 8 months (satisfactory) & - \\
\hline 51 & Fournier's gangrene & $B / L$ & 1 month & Gracilis muscle flap with SSG & $\begin{array}{l}9 \text { months (highly } \\
\text { satisfactory) }\end{array}$ & - \\
\hline 32 & Trauma & $B / L$ & 4 days & Gracilis muscle flap with SSG & $\begin{array}{l}6 \text { months (highly } \\
\text { satisfactory) }\end{array}$ & - \\
\hline 35 & Trauma & $B / L$ & 3 days & Medial thigh flap & $\begin{array}{l}12 \text { months (highly } \\
\text { satisfactory) }\end{array}$ & - \\
\hline 30 & Trauma & $B / L$ & 12 days & ALT flap & 11 months (satisfactory) & - \\
\hline 38 & Trauma & $B / L$ & Immediate & Local flap advancement with SSG & 7 months (unsatisfi ed) & Dehiscence \\
\hline 34 & Burns & $B / L$ & 2 months & Gracilis muscle flap with SSG & 6 months (satisfactory) & Dehiscence \\
\hline 42 & Burns & $B / L$ & 1 month & Local flap advancement with SSG & 8 months (satisfactory) & - \\
\hline
\end{tabular}

SSG: split skin grafting; B/L: bilateral; U/L: unilateral;ALT: anterolateral thigh

regional and muscle flaps were superior in comparison to the local flap advancement with SSG. This study did not include the assessment of sexual function, and further studies are needed.

\section{DISCUSSION}

SSG for scrotal avulsion injuries was first advocated by Millard and subsequently by Maguina. ${ }^{[4-6]}$ In cases of complete loss of penile and scrotum skin, grafting may be the most successful and simplest option in the closure of these defects. ${ }^{[4]}$ The spermatic cord can be partially retracted up into the inguinal canals, and testicles should be sutured together to minimize motion and maximize graft take. Long-term success with skin grafting for scrotal injury is excellent, and only $20 \%$ of patients require significant revisions or reconstructions. However, SSG may have certain disadvantages such as technical difficulty at recipient site, poor graft take, contraction and distortion, lack of protective sensation, and less acceptable cosmetic results. An SSG does not take if the testes have been stripped of the tunica vaginalis. SSG is a better option for 
old or debilitated patients, while young patients benefit from flap coverage.

Several locoregional cutaneous and fasciocutaneous flaps from thigh, perineal, and groin areas have been described to reconstruct the penoscrotal region. Local flap advancement provides a faster and simpler option of coverage, but the aesthetic appearance may not be pleasant to the younger patients.

The ALT flap provides excellent closure for extensive defects of the penoscrotal region because it is easy to rotate over the defect and provides excellent aesthetic results. Further thinning may be required as they are inherently bulky flaps though supra-thin flaps have also been described.

The fasciocutaneous flap of the inner thighs has excellent vascularization because of the presence of the branches of the femoral artery (internal and circumflex pudendal arteries), making the flap very safe even in diabetic and

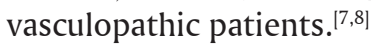

Many myocutaneous flaps have been described, including the rectus abdominis myocutaneous flap, the gracilis myocutaneous flap, and composite gastric seromuscular and omental pedicled flaps. ${ }^{[9-11]}$ These procedures produce acceptable cosmetic results, and the flaps take readily even in the contaminated environment. Limitations of muscle flaps include loss of functioning muscle, poor sensation, and scarring on thighs and lower abdomen.

Perforator-based flaps include the medial thigh flap, paraumbilical perforator-based cutaneous island flap, medial circumflex femoral artery perforator flap, and pedicled deep inferior epigastric perforator flap. ${ }^{[11,12]}$ These flaps are thin, which is aesthetically and functionally ideal for scrotum replacement. However, these flaps are technically difficult, and their blood supply is less predictable.

In conclusion, reconstruction of the penoscrotal region is challenging because it not only affects the physical and esthetic appearance but also has a major psychological and social impact to the patient. Every case needs a customized approach. The choice depends upon the surgeon's preferences, condition of the patient, and ability to achieve the best reconstructive results with the least morbidity.

\section{Financial support and sponsorship Nil.}

\section{Conflicts of interest}

There are no conflicts of interest.

\section{REFERENCES}

I. Kolehmainen M, Suominen S, Tukiainen E. Pelvic, perineal and genital reconstructions. Scand J Surg 2013;102:25-31.

2. Lee SH, Rah DK, Lee WJ. Penoscrotal reconstruction with gracilis muscle flap and internal pudendal artery perforator transposition. Urology 20I2;79:1390-4

3. Chen SY, Fu JP, Chen TM, Chen SG. Reconstruction of scrotal and perineal defects in fournier's gangrene.J Plast Reconstr Aesthet Surg 201 I;64:528-34.

4. Millard DR Jr. Scrotal construction and reconstruction. Plast Reconstr Surg 1966;38:10-5.

5. Maguiña P, Palmieri TL, Greenhalgh DG. Split thickness skin grafting for recreation of the scrotum following Fournier's gangrene. Burns 2003;29:857-62.

6. Ellabban MG. Single stage muscle flap reconstruction of major scrotal defects. Burns 2004;30:505.

7. Yang J, Ko SH, Oh SJ, Jung SW. Reconstruction of a perineoscrotal defect using bilateral medial thigh fasciocutaneous flaps. Arch Plast Surg 20I3;40:72-4.

8. Ferreira PC, Reis JC, Amarante JM, Silva AC, Pinho CJ, Oliveira IC, da Silva PN. Fournier's gangrene: a review of 43 reconstructive cases. Plast Reconstr Surg 2007; I 19:175-84.

9. Karsidag S, Akcal A, Sirvan SS, Guney S, Ugurlu K. Perineoscrotal reconstruction using a medial circumflex femoral artery perforator flap. Microsurgery 201 I;31:II6-21.

10. Parkash S, Gajendran V. Surgical reconstruction of the sequelae of penile and scrotal gangrene: a plea for simplicity. Br J Plast Surg 1984;37:354-7.

II. Gencosmanoğlu R, Bilkay U, Alper M, Gürler T, Cağdaş A. Late results of split-grafted penoscrotal avulsion injuries. JTrauma 1995;39:120I-3.

12. Monteiro E, Carvalho P, Costa P, Ferraro A. "Inner thigh lift flap" for Fournier gangrene of the scrotum. Plast Reconstr Surg 2002; I 10:1372-3. 